Article

\title{
The Effects of Beetroot Juice on Blood Pressure, Microvascular Function and Large-Vessel Endothelial Function: A Randomized, Double-Blind, Placebo-Controlled Pilot Study in Healthy Older Adults
}

\author{
Tomos Jones ${ }^{1, *}$, Emily Louise Dunn ${ }^{1}$, Jamie Hugo Macdonald ${ }^{1}$, Hans-Peter Kubis ${ }^{1}$, \\ Nicholas McMahon ${ }^{2}$ and Aamer Sandoo ${ }^{1}$ (D) \\ 1 School of Sport, Health and Exercise Sciences, Bangor University, George Building, Bangor, Gwynedd, \\ Wales LL57 2PZ, UK \\ 2 School of Human Movement and Nutrition Sciences, University of Queensland, \\ St. Lucia, QLD 4067, Australia \\ * Correspondence: tomos.jones@bangor.ac.uk; Tel.: +012-483-88-147
}

Received: 18 June 2019; Accepted: 30 July 2019; Published: 2 August 2019

\begin{abstract}
Dietary nitrate $\left(\mathrm{NO}_{3}{ }^{-}\right)$has been reported to improve endothelial function (EF) and blood pressure (BP). However, most studies only assess large-vessel EF with little research on the microvasculature. Thus, the aim of the present pilot study is to examine $\mathrm{NO}_{3}{ }^{-}$supplementation on microvascular and large-vessel $\mathrm{EF}$ and BP. Twenty older adults (63 \pm 6 years) were randomized to a beetroot juice (BRJ) or placebo (PLA) group for $28( \pm 7)$ days and attended three laboratory visitations. Across visitations, blood pressure, microvascular function and large-vessel EF were assessed by laser Doppler imaging (LDI) with iontophoresis of vasoactive substances and flow-mediated dilatation (FMD), respectively. Plasma $\mathrm{NO}_{3}{ }^{-}$concentrations, $\mathrm{BP}$ and the presence of $\mathrm{NO}_{3}{ }^{-}$reducing bacteria were also assessed. Plasma $\mathrm{NO}_{3}{ }^{-}$increased following two weeks of BRJ supplementation $(p=0.04)$ along with a concomitant decrease in systolic and diastolic BP of approximately $-6 \mathrm{mmHg}$ and $-4 \mathrm{mmHg}$, respectively ( $p=0.04 ; p=0.01$, respectively). BP remained unchanged in the PLA group. There were no significant differences in endothelium-dependent or endothelium-independent microvascular responses between groups. FMD increased by 1.5\% following two weeks of BRJ $(p=0.04)$, with only a minimal $(0.1 \%)$ change for the PLA group. In conclusion, this pilot study demonstrated that medium-term BRJ ingestion potentially improves SBP, DBP and large-vessel EF in healthy older adults. The improvements observed in the present study are likely to be greater in populations presenting with endothelial dysfunction. Thus, further prospective studies are warranted in individuals at greater risk for cardiovascular disease.
\end{abstract}

Keywords: dietary nitrate; endothelial dysfunction; endothelial function; large-vessels; microvessels; blood pressure

\section{Introduction}

The endothelium is the inner most lining of the vasculature and plays a pivotal role in regulating vascular tone via the release of several vasoactive factors [1]. One such factor is nitric oxide (NO), which is a potent vasodilator that is important for maintaining vascular homeostasis [2]. Endothelial dysfunction (ED) is characterized by a reduction in NO bioavailability and can increase cardiovascular disease (CVD) risk, particularly in older individuals [3,4]. 
Vegetables such as beetroot and spinach contain high levels of nitrate $\left(\mathrm{NO}_{3}{ }^{-}\right)$and when consumed, they can increase NO bioavailability independently of the endothelium [5]. When ingested, dietary $\mathrm{NO}_{3}{ }^{-}$is partially absorbed into the circulation and is later taken up by the salivary glands. Within the oral cavity $\mathrm{NO}_{3}{ }^{-}$becomes 10 - to 20 -fold more concentrated in the saliva [6]. Further, salivary $\mathrm{NO}_{3}{ }^{-}$ is reduced to nitrite $\left(\mathrm{NO}_{2}{ }^{-}\right)$by commensal facultative anaerobic bacteria, located on the posterior region of the tongue. After swallowing, most of the salivary $\mathrm{NO}_{2}{ }^{-}$is converted to $\mathrm{NO}$ in the acidic conditions of the stomach; however, a small percentage is transported into the circulation. Once in the circulation, $\mathrm{NO}_{2}{ }^{-}$is converted to $\mathrm{NO}$ through enzymatic and non-enzymatic reactions [7-11]. This endothelium-independent production of $\mathrm{NO}$ is commonly described as the entero-salivary $\mathrm{NO}_{3}{ }^{-}-\mathrm{NO}_{2}{ }^{-}-\mathrm{NO}$ pathway [12]. A growing body of literature identifies dietary $\mathrm{NO}_{3}{ }^{-}$as an exogenous source of NO, which has the capacity to improve endothelial function (EF) in individuals at risk of CVD [13].

A prospective study (over 14 years) in a cohort of older adults, reported that a diet low in $\mathrm{NO}_{3}{ }^{-}$rich vegetables was correlated with the prevalence of CVD mortality [14], this conclusion is also in line with previous findings from the same research group [15]. Furthermore, the high $\mathrm{NO}_{3}{ }^{-}$ content of a Mediterranean and Japanese diet has been suggested to be associated with significant blood pressure (BP) improvements $[16,17]$. Diets, which are naturally rich in $\mathrm{NO}_{3}{ }^{-}$, supplements such as beetroot juice (BRJ), have also been demonstrated to have beneficial effects on BP [9,18-25]. Although these discoveries support the cardioprotective features of dietary $\mathrm{NO}_{3}{ }^{-}$, little is known about the underlying mechanisms. In humans, EF is commonly assessed in conduit arteries using flow-mediated dilatation (FMD), which measures the endothelium-dependent dilatory response to reactive hyperaemia. In a large cohort of 68 hypertensive patients, FMD responses were significantly improved following four weeks of daily BRJ consumption [19]. Furthermore, both systolic BP (SBP) and diastolic BP (DBP) were reduced following one week of the intervention and were sustained throughout the four-week supplementation period. Interestingly, there is limited research available that has investigated the effect of $\mathrm{NO}_{3}{ }^{-}$supplementation on microvascular $\mathrm{EF}$, despite the microvasculature being the primary regulator of systemic vascular resistance (SVR) and encompassing a larger surface area than the large vessels [26]. Moreover, microvascular ED is believed to precede ED in the larger blood vessels [27]. However, due to the heterogeneity of the endothelium, no clear associations can be made between vascular beds $[28,29]$. Therefore, it is important to understand the underlying principles of microvascular EF.

Gilchrist et al. examined the effects of a two-week BRJ intervention on microvascular function, large-vessel function and BP in individuals diagnosed with type II diabetes (T2D) [30]. Large-vessel function was assessed using FMD and nitroglycerine-mediated dilatation (endothelium-independent), while microvascular function was measured using laser Doppler imaging (LDI) with iontophoresis of endothelium-dependent (acetylcholine $(\mathrm{ACh})$ ) and endothelium-independent (sodium nitroprusside (SNP)) agonists [31]. Contrary to Gilchrist and colleagues' hypothesis, the intervention did not result in any significant improvements in vascular function or BP. The authors concluded that subjects had irreversibly diminished vascular reactivity, due to having multiple risk factors for CVD. Nonetheless, a longer intervention of six weeks has been shown to improve FMD and reduce SBP in hypercholesterolemic patients, although no microvascular assessment was performed in this study [18].

Therefore, the present pilot study aims to examine the effect of BRJ supplementation on microvascular function, large-vessel EF and BP in older adults over a four-week period. We hypothesized that four weeks of daily supplementation with $\mathrm{NO}_{3}{ }^{-}$rich BRJ will increase $\mathrm{NO}$ bioavailability, along with concomitant improvements in vascular function and BP. 


\section{Materials and Methods}

\subsection{Participants}

Thirty-seven healthy older adults were recruited and assessed for eligibility by e-mail, flyers and advertisements (Figure 1). Participants were allocated to each group using stratified randomization based on age ( \pm 3 years) and gender to ensure similarities between both arms. From the sample, 16 people did not reply to the invitation, one person was excluded on medical grounds. Therefore, 20 healthy older adults (age: $63 \pm 6$ years) participated in the present study. Due to personal reasons, two individuals withdrew from the study following a week of their intervention. Participants were briefed on the nature and the purpose of the investigation before written consent was taken along with a short demographic questionnaire to ensure that they satisfied the study criteria.

To avoid the effects of the menstrual cycle, only men and post-menopausal women aged 55 or older were recruited for the study. Exclusion criteria included any history of acute coronary syndrome or established CVD, use of antihypertensive medication, chronic diseases or acute illnesses, highly trained/active individuals, diets rich in green leafy vegetables and habitual use of antibacterial mouthwash. All experimental procedures were performed in accordance with the ethical standards of the Declaration of Helsinki and approved by the institutional ethics committee (S02-16/17).

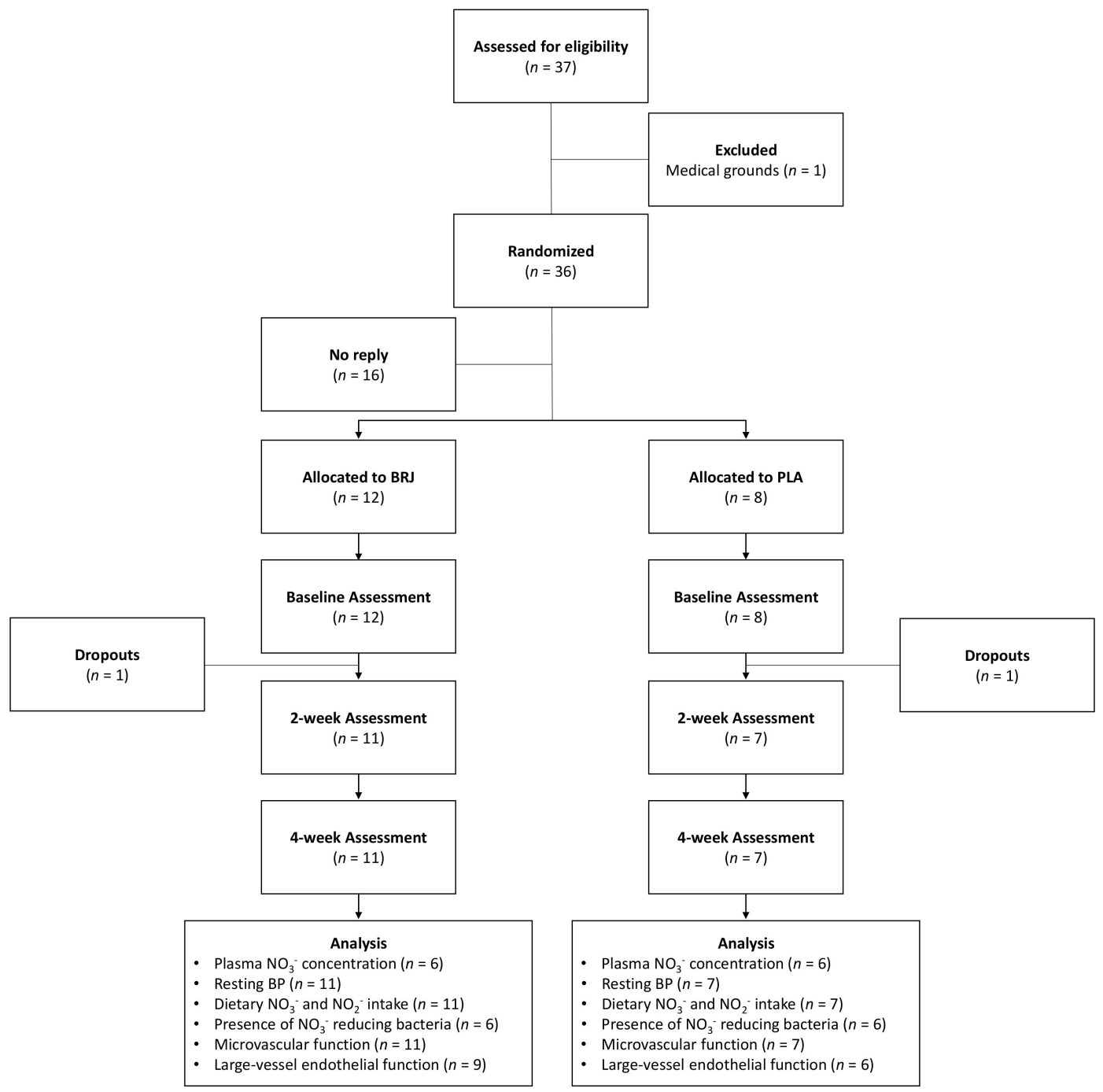

Figure 1. Consolidated standards of reporting trials (CONSORT) flowchart of study. BP = blood pressure; $\mathrm{BRJ}=$ beetroot juice; $\mathrm{NO}_{3}{ }^{-}=$nitrate and PLA = placebo. 


\subsection{Experimental Design}

A randomized placebo-controlled trial utilizing a parallel study design was used to test the hypothesis. Those assessing the outcomes were blinded to the conditions and participants were never told which treatment they were allocated to, only that both drinks had health benefits. For the duration of the study, all participants were required to attend three laboratory visits, separated by $14( \pm 7)$ days. All visits were performed in a thermoregulated laboratory $\left(21-22{ }^{\circ} \mathrm{C}\right)$, which started between the hours of 07:30-09:00 am and lasted approximately $2 \mathrm{~h}$. Participants arrived following a 12-h fast and were asked to refrain from caffeine. They were also instructed to avoid strenuous exercise $24 \mathrm{~h}$ prior to testing. Lastly, participants were asked to complete a three-day food diary and the seven-day international physical activity questionnaire (IPAQ) [32] before attending the laboratory sessions. Over the period of the study, all participants were asked to maintain their usual diet and physical activity levels.

During each visit, anthropometric data was collected prior to any other assessments, which included height, body mass, body mass index (BMI) and body fat percentage (TANITA C-300; Tanita Ltd, Japan). Venous blood samples were collected into ethylenediaminetetraacetic acid (EDTA) collection tubes and were centrifuged immediately. The plasma was separated into $500 \mu \mathrm{L}$ aliquots before being transferred to a $-80^{\circ} \mathrm{C}$ freezer for later analysis. Following the blood sample, a tongue scrape sample, containing potential nitrate reducing bacteria, was collected from the posterior region of the tongue. Samples were transferred into a $\mathrm{NO}_{3}{ }^{-}$medium and immediately incubated. Subsequently, participants were asked to lie down for $10 \mathrm{~min}$ before three separate automated BP measurements were taken (separated by $2 \mathrm{~min}$ ) and the mean value was recorded. Whilst remaining in a recumbent position, vascular function of the small and large blood vessels was assessed (separated by $15 \mathrm{~min})$.

\subsection{Drink Intervention}

Daily consumption of the active or placebo (PLA) treatment was instructed for the duration of their enrolment. The active treatment was a $70 \mathrm{~mL} \mathrm{NO}_{3}{ }^{-}$rich BRJ drink (Beet-It Sport Shot 400; James White Ltd, Ashbocking, UK), providing approximately $400 \mathrm{mg}$ of $\mathrm{NO}_{3}{ }^{-}$each day. For the PLA group, prune juice (Sunsweet Growers Inc., Kingston upon Hull, UK) was selected because of the negligible $\mathrm{NO}_{3}{ }^{-}$levels $(<0.01 \mathrm{mM})$ [33] and similar consistency and colour to BRJ. Additionally, carbohydrate and fibre content of both treatments have been reported to be similar [33]. All participants were asked to consume their allocated drink in the morning and to keep it consistent for the duration of the study, with the exception of testing days.

\subsection{Dietary $\mathrm{NO}_{3}{ }^{-}$and $\mathrm{NO}_{2}{ }^{-}$Intake}

The $\mathrm{NO}_{3}{ }^{-}$and $\mathrm{NO}_{2}{ }^{-}$content was determined by a database containing $\mathrm{NO}_{3}{ }^{-}$and $\mathrm{NO}_{2}{ }^{-}$values from 7703 foods and beverage records from 432 publications [34]. To develop the most accurate and appropriate values in terms of the study population location, a similar method previously described [35] was used with priority given to: 1) The UK/European countries from 1990 to present; 2) the UK/European countries from 1960-1989;3) countries with predominately Western diets (Australia, U.S and Canada) from 1990 to present; 4) countries with predominately Western diets from 1960-1989 and 5) countries with predominately non-Western diets. The cut-off dates were chosen to account for changes in laboratory methods, food preservation techniques and manufacturing technologies (the addition of ascorbate during meat processing, added to reduce the formation of nitrosamines), and legislation regulating the amounts of $\mathrm{NO}_{3}{ }^{-}$and $\mathrm{NO}_{2}{ }^{-}$used in the curing process created significant reductions in food and beverages $[36,37]$.

$\mathrm{NO}_{3}{ }^{-}$and $\mathrm{NO}_{2}{ }^{-}$intake was calculated by multiplying the food or beverage item consumed (grams per day) as the weighted mean value of that item identified using the multistep process mentioned above. Weighted mean was selected as some mean values were adversely affected by extreme values. 
If a $\mathrm{NO}_{3}{ }^{-}$or $\mathrm{NO}_{2}{ }^{-}$value was unattainable a value of $0 \mathrm{mg} / \mathrm{g}$ was assigned to the food or beverage item. Cooking methods such as baked, blanched, boiled, broiled, cooked, fried, microwaved, raw and steamed were reported when relevant and available.

If a food or beverage item's serving amount was missing from the recall data, the recommended serving size amount was calculated using summary estimates (in grams) as defined by standard serving sizes in nutritional analysis software $[38,39]$. In the case of multicomponent foods (e.g., pizza, juices, salad mix, soup and curries), nutrient values were determined by calculating the $\mathrm{NO}_{3}{ }^{-}$and $\mathrm{NO}_{2}{ }^{-}$content of all ingredients contained in the recipe list, or in the case of commercial products, looking at the ingredients list or using the recipe reproduction [40]. Recipes were selected from reliable and common online kitchen resource materials. Total $\mathrm{NO}_{3}{ }^{-}$and $\mathrm{NO}_{2}{ }^{-}(\mathrm{mg} /$ day) were determined by calculating the sum of daily $\mathrm{NO}_{3}{ }^{-}$and $\mathrm{NO}_{2}{ }^{-}$values.

\subsection{Presence of $\mathrm{NO}_{3}{ }^{-}$Bacteria}

A tongue scraping was collected from each participant during their first visit following an oral examination to ensure there were no signs of any mouth infections. The scrapings were performed using a disposable acrylic spatula from the posterior region of the tongue and were collected into sterile disposable pipette (Fisher Scientific, Cat. No. 13489108). Samples were transferred into $6 \mathrm{~mL}$ of $\mathrm{NO}_{3}{ }^{-}$rich medium (Ingredients per litre of deionized water: Pancreatic Digest of Gelatin 5.0 g; Beef Extract: 3.0 g; Potassium Nitrate: 1.00 g; Hardy Diagnostics, Cat. No. K42) and incubated for $54 \mathrm{~h}$ at $37{ }^{\circ} \mathrm{C}, 95 \%$ humidity and $5 \% \mathrm{CO}_{2}$. To ensure a similar inoculum size, the weight gain of the broth was kept constant at approximately $10 \mu \mathrm{g}$.

Following incubation, $1 \mathrm{~mL}$ of the $\mathrm{NO}_{3}{ }^{-}$broth was extracted through a Puradisc 25 Polyethersulfone $0.2 \mu \mathrm{m}$ sterilizing grade filter (Fisher Scientific, Cat. No. 6780-2502) to ensure that any bacteria were eliminated. Content of the syringe was then emptied into separate $500 \mu \mathrm{L}$ aliquots and immediately frozen at $-80{ }^{\circ} \mathrm{C}$ for later analysis of $\mathrm{NO}_{3}{ }^{-}$. The levels of $\mathrm{NO}_{3}{ }^{-}$in the medium were analysed before and after incubation. Reductions in $\mathrm{NO}_{3}{ }^{-}$levels are expressed as a percentage change $\left(\Delta \mathrm{NO}_{3}{ }^{-} \%\right)$, in order to determine the presence of $\mathrm{NO}_{3}{ }^{-}$reducing bacteria. All the $\mathrm{NO}_{3}{ }^{-}$analyses are described in more detail in Section 2.8.

\subsection{Microvascular Function}

Iontophoresis administration of ACh (Miochol-E, Novartis, UK) and SNP (Nitroprussiat Fides, Rottapharm SL, Spain) was performed using an iontophoresis controller (MIC-Ie, Moor Instruments Ltd, UK) in order to assess cutaneous endothelium-dependent and endothelium-independent vasodilation, respectively. Perfusion changes on the anterior surface of the forearm in response to the delivery of both vasoactive drugs were assessed using LDI, which measures blood flux (AU). The full protocol that was used for this study has been described in detail previously [41]. In summary, one baseline scan was performed before a series of ten scans with an iontophoresis charge of $30 \mu \mathrm{A}$ was delivered to administer $1 \% \mathrm{ACh}$ and $1 \%$ SNP. ACh and SNP drugs were diluted with $0.9 \%$ saline and delivered into the skin via an anode and cathode internal electrode Perspex chamber (Ø22 mm; ION 6, Moor Instruments Ltd, UK), respectively. Following ten scans with iontophoresis, two further recovery scans were performed without the delivery of the vasoactive drugs.

The exposure-time-response protocol took approximately 15-20 min and all of the scans were performed in natural lighting conditions, with most of the ambient lighting restricted. Additionally, the settings of the laser Doppler imager (moorLDI2-IR, Moor Instruments, Axminster, Devon, UK) were kept consistent for all scans. Measurements of perfusion were carried out offline using the moorLDI Review V6.1 software and results are presented as a percentage change in perfusion from baseline $\left(\frac{\text { Peak Flux-Baseline Flux }}{\text { Baseline Flux }} \times 100=\mathrm{ACh} \%\right.$ or SNP\%). 


\subsection{Large-Vessel Endothelial Function}

The FMD procedure is a non-invasive technique that is commonly used on the brachial artery as an assessment of global large-vessel EF. Several published guidelines are available for this technique [42-44], however the present study used Sandoo and Kitas' protocol [41]. Briefly, a 2 min baseline ultrasound scan of the brachial artery was followed by $5 \mathrm{~min}$ of arterial occlusion, achieved by inflating a BP cuff that was placed around the wrist to $220 \mathrm{mmHg}$. After a $5 \mathrm{~min}$ period of ischemia, the BP cuff was deflated rapidly, and a further 3 min scan of the artery was performed.

A Siemens Acuson X300 Ultrasound scanner was used with a multifrequency linear-array vascular probe set at 7.3 MHz (Siemens PLC, Camberley, UK) to perform the FMD procedure. B-mode images were captured at 15 frames per second to record a $120 \mathrm{~s}$ baseline and a $210 \mathrm{~s}$ clip following 5 min of occlusion. To capture the initial reactive hyperaemic response to the deflation of the BP cuff, the recording was initiated $30 \mathrm{~s}$ before cuff release; therefore, only $180 \mathrm{~s}$ was used for the analysis. Images were analysed offline using an automated edge detection software (Brachial Analyser, Medical Imaging Applications, USA). The Brachial Analyser software is capable of detecting the peak of the R-wave, therefore, this inbuilt feature was used to include only the images at the peak of the R-wave. Frames that did not meet the recommended quality standard (confidence threshold $<70 \%$ ) were rejected. From the frames that were accepted, the change in diameter from baseline to peak was calculated as follows, $\frac{\text { Peak Diameter-Baseline Diameter }}{\text { Baseline Diameter }} \times 100=$ FMD $\%$. To account for the differences in baseline diameter, all the data was allometrically scaled as per the Atkinson and Batterham guidelines [45]. The coefficient of variation for the sonographer (DTJ) was reported as $8.5 \%$

\subsection{Analysis of $\mathrm{NO}_{3}{ }^{-}$Concentration}

Whole venous blood samples were collected into EDTA collection tubes following a $12 \mathrm{~h}$ fast. Samples were immediately stored on ice or placed in a pre-chilled $\left(4^{\circ} \mathrm{C}\right)$ centrifuge. Once samples were centrifuged, $500 \mu \mathrm{L}$ plasma aliquots were instantly stored at $-80^{\circ} \mathrm{C}$. Prior to analysis, plasma samples were thawed and centrifuged again through an Amicon $30 \mathrm{kDa}$ molecular weight filter to reduce protein content [46]. Similarly, the sample of $\mathrm{NO}_{3}{ }^{-}$medium, for determining the presence of bacteria (Section 2.5), was also filtered in the same manner. Analysis of $\mathrm{NO}_{3}{ }^{-}$concentrations was performed using the Griess Reagent system as previously described by Miranda et al. [47]. Blood samples were analysed at baseline, week 2 (WK2) and week 4 (WK4), whilst medium samples were only analysed at baseline. Medium samples were diluted accordingly to ensure the $\mathrm{NO}_{3}{ }^{-}$values would fall within the standard range. Sodium nitrate was used for standard quantification and the results were expressed in micromoles per litre $(\mu \mathrm{M})$. The coefficients of variation $(n=35$, in duplicate $)$ of the methods were $2.9 \%$ to intra-assay and $4.0 \%$ to inter-assay.

\subsection{Statistical Analysis}

Per-protocol analysis was utilized for the present study. The assumption of normality, homogeneity of variances and sphericity were examined with the Shapiro-Wilk, Levene's and Mauchly tests, respectively. For the primary and secondary outcomes, the change in each parameter was compared between placebo and dietary nitrate arms by an unpaired Student $t$-test. Changes in parameters over time were compared by repeated measures analysis of variance (ANOVA) with Bonferroni post hoc tests (to account for multiple comparisons) and unpaired Student $t$-test for comparisons between groups. The level for statistical significance taken was $p<0.05$ for all analyses. If groups were different at baseline for any of the dependent variables, an analysis of covariance (ANCOVA) was used to test for differences between groups at two weeks and four weeks with baseline values being included as the covariate. Results for all normally distributed data are presented as mean \pm standard deviation (SD). Data that were skewed were log transformed, however the median and interquartile range (IQR) of the raw data are presented. All analyses were performed using a commercially available statistical package (IBM SPSS Statistics version 22 for Windows, Chicago, IL, USA). 


\section{Results}

A total of 18 participants completed all three study visits between January 2017 to December 2018. According to verbal confirmation, both interventions were well tolerated for the duration of the study. No serious adverse events were experienced, however common side effect such as beeturia and faecal discolouration were reported. Baseline demographic characteristics were similar for both treatment allocations (Table 1). None of the participants had any uncontrolled conditions and were considered to be healthy individuals.

Table 1. Baseline characteristics stratified by treatment allocation.

\begin{tabular}{lccc}
\hline Treatment Allocation & BRJ & PLA & Significance \\
\hline Demographics & & & \\
$n$ & 11 & 7 & 0.34 \\
Age $(\mathrm{y})$ & $65 \pm 8$ & $61 \pm 5$ & 0.62 \\
Height $(\mathrm{cm})$ & $167.4 \pm 9.5$ & $165.3 \pm 6.2$ & 0.99 \\
Weight $(\mathrm{kg})$ & $73.2 \pm 16.6$ & $73.3 \pm 8.0$ & 0.80 \\
BMI $\left(\mathrm{kg} / \mathrm{m}^{2}\right)$ & $26.2 \pm 6.3$ & $26.9 \pm 2.1$ & 0.51 \\
Body Fat $(\%)$ & $30.7 \pm 10.5$ & $33.8 \pm 7.7$ & \\
Dietary Intake & & & 0.78 \\
$\mathrm{NO}_{3}^{-}$ & $151.8 \pm 77.8$ & $185.3 \pm 75.7$ & 0.49 \\
$\mathrm{NO}_{2}^{-}$ & $7.4 \pm 3.8$ & $5.8 \pm 1.9$ & \\
$\mathrm{Clinical} \mathrm{BP}_{\text {SBP }}$ & & & 0.46 \\
DBP & $129 \pm 12$ & $124 \pm 14$ & 0.23 \\
\hline
\end{tabular}

Data are presented as mean \pm SD. $p$-values shown in the last column for an unpaired Student $t$-test. BMI $=$ body mass index; $\mathrm{BRJ}=$ beetroot juice; $\mathrm{DBP}=$ diastolic blood pressure; $\mathrm{NO}_{3}{ }^{-}=$nitrate; $\mathrm{NO}_{2}{ }^{-}=$nitrite; $\mathrm{PLA}=$ placebo and $\mathrm{SBP}=$ systolic blood pressure.

\subsection{Plasma Nitrate Concentrations}

Plasma samples were analysed for 12 individuals (6 BRJ; 6 PLA), due to insufficient volumes from the remaining six participants (Figure 2). Across the duration of the study, $\mathrm{NO}_{3}{ }^{-}$levels were highest in the BRJ group following two weeks of supplementation but declined slightly from WK2 to WK4. Mean plasma $\mathrm{NO}_{3}{ }^{-}$concentrations of the BRJ group increased from $34 \pm 8 \mu \mathrm{M}$ to $132 \pm 83 \mu \mathrm{M}$ following two weeks ( $p=0.04$ ), with concentrations measuring at $78 \pm 41 \mu \mathrm{M}$ at four weeks $(p=0.60)$. Furthermore, $\mathrm{NO}_{3}{ }^{-}$levels were significantly greater compared to PLA treatment at WK2 and WK4 $\left(p=0.02 ; p=0.03\right.$, respectively). There were no significant changes in plasma $\mathrm{NO}_{3}{ }^{-}$concentration within the PLA group.

\subsection{Resting Blood Pressure}

Following two weeks of BRJ ingestion, SBP reduced by $-6 \pm 7 \mathrm{mmHg}$ and DBP by $-4 \pm 3 \mathrm{mmHg}$ $(p=0.04 ; p=0.01$, respectively). However, from WK2 to WK4, SBP increased by $2 \pm 7 \mathrm{mmHg}(p=1.00)$ and DBP by $2 \pm 4 \mathrm{mmHg}(p=0.49)$. Over the four-week course of the BRJ treatment, SBP reduced by $-4 \pm 10 \mathrm{mmHg}(p=0.67)$ and DBP by $-2 \pm 6 \mathrm{mmHg}(p=0.75)$. Within the PLA treatment group, SBP reduced by $-1 \pm 10 \mathrm{mmHg}$ following two weeks and DBP by $0 \pm 5(p=1.00)$. From WK2 to WK4, SBP was further reduced by $-4 \pm 7 \mathrm{mmHg}(p=0.70)$ and DBP by $0 \pm 3 \mathrm{mmHg}(p=1.00)$. Over the four-week course of the PLA treatment, SBP reduced by $-5 \pm 6 \mathrm{mmHg}(p=0.17)$ and DBP by $-1 \pm 4 \mathrm{mmHg}(p=1.00)$. None of the BP changes for PLA treatment reached statistical significance. Additionally, no significant differences were observed between the groups at any time point (Figure 3). Similarly, the changes in BP were not significant between the two groups after two and four weeks (Table 2). 


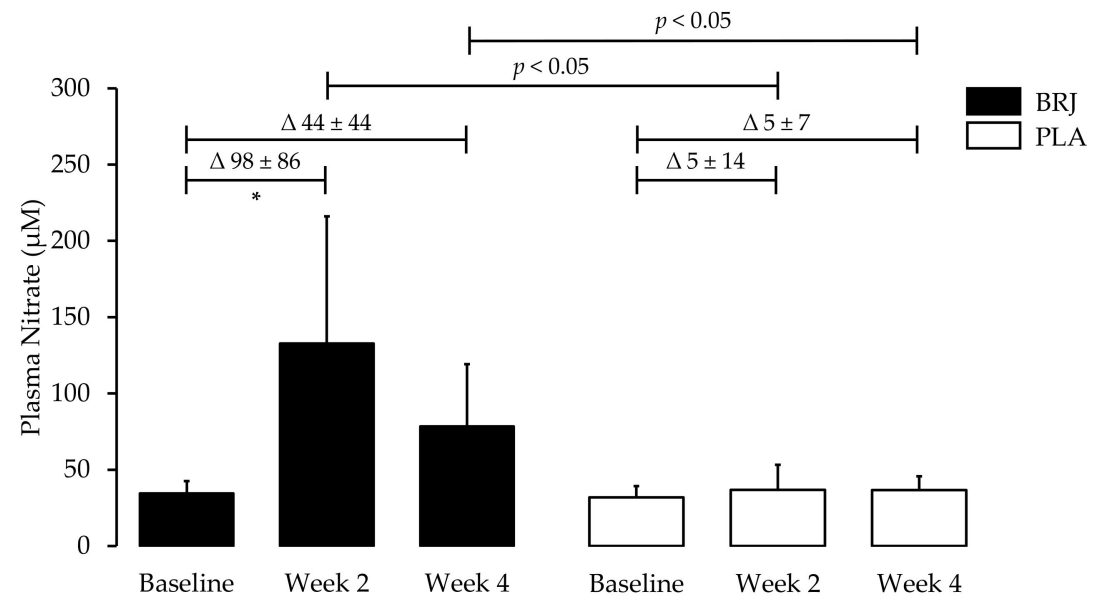

Figure 2. The effects of four weeks of BRJ consumption or PLA on plasma nitrate. Beetroot juice consumption increases plasma nitrate in healthy older adults. Data are expressed as mean \pm SD. * Significance shown for comparisons within treatment allocations of the change between baseline, week 2 and week $4, p<0.05$ for Bonferroni post hoc test. Significance shown for comparisons between treatment allocations for an unpaired Student $t$-test, $p<0.05$. BRJ $=$ beetroot juice; PLA = placebo.

A

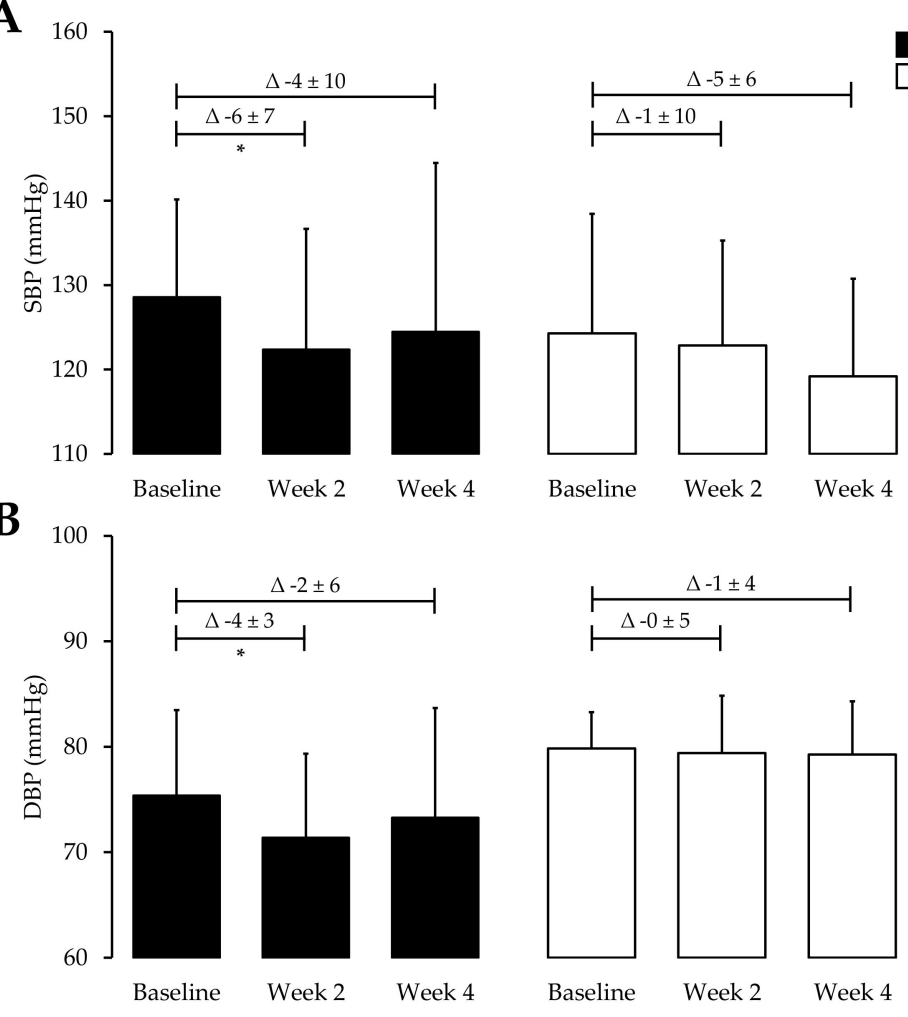

Figure 3. The effects of four weeks of BRJ consumption or PLA on BP. Beetroot juice consumption reduces (A) SBP and (B) DBP in healthy older adults. Data are expressed as mean \pm SD. * Significance shown for comparisons within treatment allocations of the change between baseline, week 2 and week $4, p<0.05$ for a Bonferroni post hoc test. BRJ = beetroot juice; DBP = diastolic blood pressure; PLA $=$ placebo and SBP $=$ systolic blood pressure . 
Table 2. Changes in vascular outcomes during the intervention.

\begin{tabular}{|c|c|c|c|c|c|c|c|c|c|c|c|c|c|c|c|}
\hline & \multicolumn{6}{|c|}{ BRJ } & \multicolumn{6}{|c|}{ PLA } & \multicolumn{3}{|c|}{ P (Comparison between BRJ and PLA) } \\
\hline & Baseline & Week 2 & Week 4 & $\Delta$ & $\Delta$ & $\Delta$ & Baseline & Week 2 & Week 4 & $\Delta$ & $\Delta$ & $\Delta$ & $\Delta$ & $\Delta$ & $\Delta$ \\
\hline & & & & Week 2 - Baseline & Week 4 - Week 2 & Week 4-Baseline & & & & Week 2 - Baseline & Week 4 - Week 2 & Week 4-Baseline & Week 2 - Baseline & Week 4 - Week 2 & 2 Week 4-Baseline \\
\hline $\begin{array}{c}\text { SBP } \\
(\mathrm{mmHg})\end{array}$ & $\begin{array}{c}129 \pm \\
12\end{array}$ & $\begin{array}{c}122 \pm \\
14\end{array}$ & $\begin{array}{c}124 \pm \\
20\end{array}$ & $-6 \pm 7$ & $2 \pm 7$ & $-4 \pm 10$ & $\begin{array}{c}124 \pm \\
14\end{array}$ & $\begin{array}{c}123 \pm \\
12\end{array}$ & $\begin{array}{c}119 \pm \\
11\end{array}$ & $-1 \pm 10$ & $-4 \pm 7$ & $-5 \pm 6$ & 0.23 & 0.12 & 0.84 \\
\hline $\begin{array}{c}\text { DBP } \\
(\mathrm{mmHg})\end{array}$ & $75 \pm 8$ & $71 \pm 8$ & $73 \pm 10$ & $-4 \pm 3$ & $2 \pm 4$ & $-2 \pm 6$ & $79 \pm 3$ & $79 \pm 5$ & $79 \pm 5$ & $0 \pm 5$ & $0 \pm 3$ & $-1 \pm 4$ & 0.08 & 0.29 & 0.55 \\
\hline $\begin{array}{l}\mathrm{ACh} \\
(\%)\end{array}$ & $\begin{array}{c}447.30 \\
\pm \\
364.82\end{array}$ & $\begin{array}{c}304.59 \\
\pm \\
326.87\end{array}$ & $\begin{array}{c}343.65 \\
\pm \\
425.80\end{array}$ & $\begin{array}{c}-142.71 \pm \\
295.97\end{array}$ & $\begin{array}{c}39.05 \pm \\
411.12\end{array}$ & $\begin{array}{c}-103.66 \pm \\
340.20\end{array}$ & $\begin{array}{c}66.16 \pm \\
65.02\end{array}$ & $\begin{array}{c}116.30 \\
\pm 88.28\end{array}$ & $\begin{array}{c}68.58 \pm \\
71.58\end{array}$ & $\begin{array}{c}50.14 \pm \\
142.28\end{array}$ & $\begin{array}{c}-47.72 \pm \\
143.64\end{array}$ & $2.42 \pm 71.20$ & 0.13 & 0.60 & 0.43 \\
\hline $\begin{array}{l}\text { SNP } \\
(\%)\end{array}$ & $\begin{array}{c}537.53 \\
\pm \\
434.81\end{array}$ & $\begin{array}{c}449.00 \\
\pm \\
451.84\end{array}$ & $\begin{array}{c}358.91 \\
\pm \\
534.79\end{array}$ & $\begin{array}{l}-88.54 \pm \\
341.96\end{array}$ & $\begin{array}{l}-90.09 \pm \\
497.00\end{array}$ & $\begin{array}{c}-178.62 \pm \\
357.99\end{array}$ & $\begin{array}{c}216.99 \\
\pm \\
305.40\end{array}$ & $\begin{array}{c}122.15 \\
\pm \\
143.08\end{array}$ & $\begin{array}{c}171.28 \\
\pm \\
279.98\end{array}$ & $\begin{array}{c}-98.84 \pm \\
373.01\end{array}$ & $\begin{array}{l}49.13 \pm \\
364.91\end{array}$ & $\begin{array}{c}-45.71 \pm \\
394.21\end{array}$ & 0.97 & 0.53 & 0.47 \\
\hline $\begin{array}{c}\text { FMD } \\
(\%)\end{array}$ & $\begin{array}{c}5.26 \pm \\
1.75\end{array}$ & $\begin{array}{c}7.12 \pm \\
2.12\end{array}$ & $\begin{array}{c}7.15 \pm \\
2.09\end{array}$ & $1.50 \pm 1.81$ & $0.02 \pm 1.03$ & $1.53 \pm 1.49$ & $\begin{array}{c}6.38 \pm \\
2.36\end{array}$ & $\begin{array}{c}6.45 \pm \\
2.52\end{array}$ & $\begin{array}{c}6.91 \pm \\
2.63\end{array}$ & $0.07 \pm 0.83$ & $0.46 \pm 0.33$ & $0.54 \pm 0.97$ & 0.10 & 0.34 & 0.18 \\
\hline
\end{tabular}

Data are presented as mean $+\mathrm{SD}$. An unpaired Student $t$-test was used to evaluate differences in changes $(\Delta)$ between the two groups. ACh $=$ acetylcholine; BRJ $=$ beetroot juice; $\mathrm{DBP}=$ diastolic blood pressure; FMD = flow-mediated dilatation; $\mathrm{PLA}=$ placebo; $\mathrm{SBP}$ = systolic blood pressure and $\mathrm{SNP}=$ sodium nitroprusside. 


\subsection{Dietary $\mathrm{NO}_{3}^{-}$and $\mathrm{NO}_{2}^{-}$Intake}

Analysis of the three-day self-report food diary was performed in order to quantify the $\mathrm{NO}_{3}{ }^{-}$and $\mathrm{NO}_{2}{ }^{-}$intake at baseline, before their second visitation and before their final visitation (Table 3). At each time-point, the intake of $\mathrm{NO}_{3}{ }^{-}$and $\mathrm{NO}_{2}{ }^{-}$did not significantly differ between groups. Furthermore, no difference was observed over the four weeks within the BRJ and PLA groups.

Table 3. Quantification of the amount of $\mathrm{NO}_{3}{ }^{-}$and $\mathrm{NO}_{2}{ }^{-}$, measured with a three-day self-report food diary.

\begin{tabular}{cccc}
\hline Treatment Allocation & BRJ & PLA & Significance \\
\hline $\mathrm{NO}_{3}{ }^{-}(\mathrm{mg})$ & & & \\
Baseline & $151.8 \pm 77.8$ & $185.3 \pm 75.7$ & 1.00 \\
WK2 & $182.5 \pm 72.4$ & $200.2 \pm 63.2$ & 0.66 \\
WK4 & $195.4 \pm 66.9$ & $190.4 \pm 113.6$ & 0.47 \\
$\mathrm{NO}_{2}^{-}(\mathrm{mg})$ & & & \\
Baseline & $7.4 \pm 3.8$ & $5.8 \pm 1.9$ & 0.12 \\
WK2 & $6.2 \pm 4.0$ & $8.2 \pm 2.9$ & 0.43 \\
WK4 & $8.1 \pm 4.4$ & $5.1 \pm 2.3$ & 0.07 \\
\hline
\end{tabular}

Data are presented as mean \pm SD. $p$-values shown in the last column for an unpaired Student $t$-test. BRJ $=$ beetroot juice; $\mathrm{NO}_{3}{ }^{-}=$nitrate; $\mathrm{NO}_{2}{ }^{-}=$nitrite; $\mathrm{PLA}=$ placebo; $\mathrm{WK} 2$ = week 2 and $\mathrm{WK} 4=$ week 4.

\subsection{Presence of $\mathrm{NO}_{3}{ }^{-}$Reducing Bacteria}

Twelve participants were included for the oral microbiome assessment (6 BRJ; 6 PLA). This assessment was used to determine the presence of $\mathrm{NO}_{3}{ }^{-}$reducing bacteria. Every participant who was included for this assessment demonstrated the capacity to reduce $\mathrm{NO}_{3}{ }^{-}$. Following $54 \mathrm{~h}$ in incubation, the tongue scrape samples from each participant successfully reduced all of the $\mathrm{NO}_{3}{ }^{-}$in the broth medium, meaning a $100 \%$ reduction of the available $\mathrm{NO}_{3}{ }^{-}$substrate. These results confirmed the presence of $\mathrm{NO}_{3}{ }^{-}$reducing bacteria in the oral cavity of the 12 participants included for this analysis.

\subsection{Microvascular Function}

Blood flux was quantified by calculating the median rather than the mean for each region of interest. This is due to the fact the laser Doppler imaging data will rarely have Gaussian distribution [48]. The flux responses to ACh and SNP were not normally distributed for any of the laboratory visits, therefore log-transformed data was used to test for differences. However, the results are presented using raw data as percentage changes in flux with IQR (Figure 4). Contrary to our hypothesis, no significant differences in endothelium-dependent (ACh) or endothelium-independent (SNP) microvascular responses were observed over the three visitations.

As expected, flux values increased in response to the iontophoresis of ACh for both groups. During the baseline visit, the median responses were measured at 380.0\% (IQR: 743.6\%) for the BRJ group and $44.3 \%$ (IQR: 133.3) for the PLA $(p=0.03$ ). Significant differences between groups were reported at baseline; therefore, these values were used as a covariate in ANCOVA analysis to test for difference between groups at WK2 and WK4. Median responses at WK2 were 234.9\% (IQR: 473.8\%) for BRJ group and $117.8 \%$ (IQR: $141.8 \%)$ for the PLA group $(p=0.75)$. Furthermore, no significant differences between groups was observed at WK4, with the BRJ response measured at $108.1 \%$ (IQR: $665.45 \%$ ) and PLA response measured at 59.1\% (IQR: 130.94\%; $p=0.42$ ). Similarly, the changes in ACh were not significant between the two groups after two and four weeks (Table 2).

As expected, flux values increased in response to the iontophoresis of SNP for both groups. During the baseline visit, the median responses were measured at 510.0\% (IQR: $864.5 \%$ ) for the BRJ group and 112.3\% (IQR: 131.0$)$ for the PLA $(p=0.15)$. Median responses at WK2 were $260 \%$ (IQR: $906.4 \%$ ) for BRJ group and $73.1 \%$ (IQR: $223.3 \%$ ) for the PLA group $(p=0.43$ ). Furthermore, no significant differences between groups was observed at WK4, with the BRJ response measured at 33.4\% (IQR: 830.8\%) and 
PLA response measured at 107.0\% (IQR: $171.9 \% ; p=0.80$ ). Similarly, the changes in SNP were not significant between the two groups after two and four weeks (Table 2).

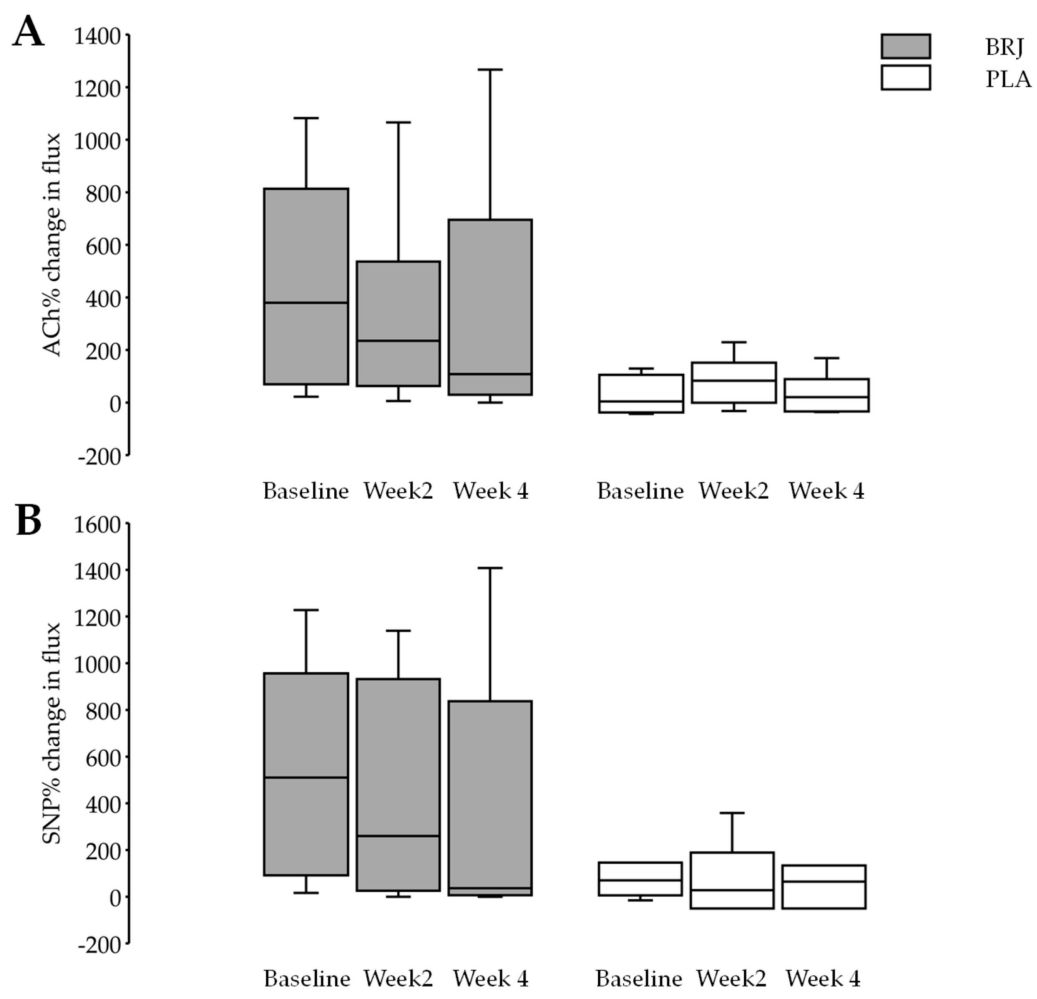

Figure 4. The effect of treatments on laser Doppler imaging (LDI) with iontophoresis is over four weeks ( $n=18)$. Log-transformed data was used for all analyses, as the untransformed data was not normally distributed. Untransformed data expressed as median (IQR). ACh = acetylcholine; LDI = laser Doppler imaging; IQR = interquartile range and $\mathrm{SNP}=$ sodium nitroprusside.

\subsection{Large-Vessel Endothelial Function}

Data loss occurred for three participants, therefore only 15 participants (9 BRJ; 6 PLA) were included for the main FMD analysis. FMD responses increased from baseline to WK2 for the BRJ treatment and the improvements were sustained until WK4. At baseline, endothelium-dependent vasodilation was $5.6 \% \pm 1.8 \%$ in the BRJ group and for the PLA group it was $6.4 \% \pm 2.5 \%(p=0.49)$. Within the BRJ group, FMD values increased by $1.5 \% \pm 1.8 \%$ at WK2 $(p=0.04)$, however values only increased by $0.1 \% \pm 0.8 \%$ in the PLA groups $(p=0.84)$. After four weeks, FMD values increased by $1.5 \% \pm 1.5 \%$ for the BRJ treatment $(p=0.01)$. The PLA group failed to reach any significance after four weeks, although a small improvement of $0.5 \% \pm 1.0 \%$ was reported $(p=0.23)$. Further to this, no main effect between groups was found at WK2 $(p=0.58)$ or WK4 $(p=0.85$; Figure 5A). Similarly, the changes in FMD were not significant between the two groups after two and four weeks (Table 2). Using appropriate allometric scaling methods on the data did not change any of the outcomes; however, corrected data is presented in Figure 5B. 
A

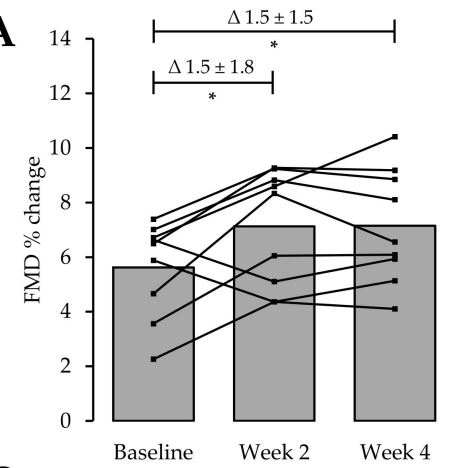

B

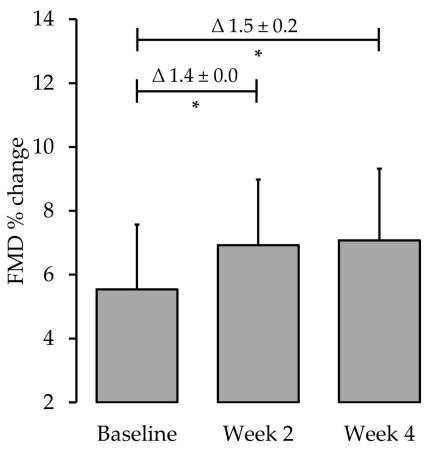

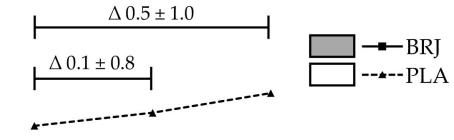

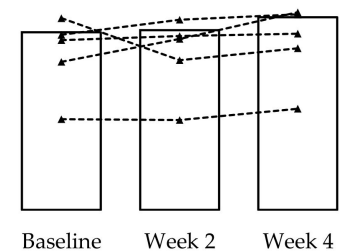

Baseline Week 2 Week 4
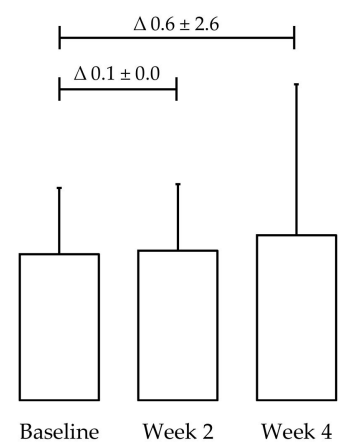

Figure 5. The effects of four weeks of BRJ consumption or PLA on FMD. Beetroot juice consumption increases FMD responses in healthy older adults. Both (A) uncorrected and (B) allometrically scaled data are expressed as mean $\pm \mathrm{SD}$ and individual data for uncorrected data. ${ }^{*}$ Significance shown for comparisons within treatment allocations of the change between baseline, week 2 and week 4 , $p<0.05$ for the Bonferroni post hoc test. BRJ = beetroot juice; FMD $=$ flow-mediated dilatation and PLA = placebo.

\section{Discussion}

The findings from the present pilot study indicate that medium-term BRJ supplementation could potentially improve large-vessel EF and BP in healthy older adults. Despite our findings showing no main effect between groups, significant improvements in both SBP and DBP were reported within the BRJ group after two weeks. However, the changes in BP were not significantly different to BP changes in the PLA group. After four weeks, SBP and DBP values remained lower than baseline within the $\mathrm{BRJ}$ group, but were no longer significant. Interestingly, a large reduction of $-5 \pm 6 \mathrm{mmHg}$ in SBP was observed in the PLA group following four weeks and could potentially mask any between group effects. Although the exact cause of these improvements was unknown, we concluded that they could be due to the increase in IPAQ scores, which were not observed in the BRJ group. Alternatively, it has been proposed that on average systolic and diastolic BP reduce by $15 \mathrm{mmHg}$ and $7 \mathrm{mmHg}$ respectively by the third visit with a physician [49]. However, given that both groups would likely experience this effect, the magnitude of $\mathrm{BP}$ change in BRJ is likely to be mediated by the increased $\mathrm{NO}_{3}{ }^{-}$levels from the BRJ. Contrary to our hypothesis, the present pilot study observed no changes in microvascular function in response to the intervention. This null finding cannot be explained by non-responders as we demonstrated that participants had elevated plasma $\mathrm{NO}_{3}{ }^{-}$levels and a full capacity to convert the $\mathrm{NO}_{3}{ }^{-}$within the oral microbiome.

A vast amount of research has demonstrated the significance of nutritional therapy for cardiovascular health, particularly for high $\mathrm{BP}[43,44]$. In recent years, dietary $\mathrm{NO}_{3}{ }^{-}$is one nutraceutical that has been identified as a treatment for hypertension (average reductions: $\mathrm{SBP} ;-4.4 \mathrm{mmHg}$ and DBP; $-1.1 \mathrm{mmHg}$ ) [50]. Aside from the present pilot study, only a few have tested medium-term interventions on EF and BP in humans ( $\geq 4$ weeks) [18,19]. According to a comprehensive review by Carlström et al., this therapeutic effect is achieved through several mechanisms [51]. The evidence implies that 
improvements in EF were the primary explanation for these reductions. Indeed, exogenous sources of NO have been shown to induce vasodilation, which consequently reduces SVR [52]. Interestingly, these vascular responses to dietary $\mathrm{NO}_{3}{ }^{-}$consumption occur shortly after ingestion and coincide with $\mathrm{BP}$ reductions. In support of this statement, Bondonno et al. demonstrated significant improvements in FMD responses $2 \mathrm{~h}$ post $\mathrm{NO}_{3}{ }^{-}$ingestion, which were also accompanied by reductions in SBP.

To date, the longest intervention performed in humans is a six-week study, in hypercholesterolemic individuals [18]. The authors reported that over the duration of the study, FMD responses improved by $4 \%$ and both SBP and DBP were reduced $(-4.1 \mathrm{mmHg}$ and $-1.5 \mathrm{mmHg}$, respectively). Further support for medium-term supplementation was published by Kapil et al. in 2015. They reported a 20\% improvement in FMD responses following four weeks of BRJ supplementation in a hypertensive cohort, which was accompanied by reductions in SBP and DBP $(-7.7 \mathrm{mmHg}$ and $-2.4 \mathrm{mmHg}$, respectively) [19]. Similarly, the present pilot study found improvements of 27\% in FMD responses and reductions of $-4.1 \mathrm{mmHg}$ and $-2.1 \mathrm{mmHg}$ in SBP and DBP, respectively. Despite our pilot data not showing a significant effect between the groups, collectively, these positive findings imply that medium-term use of $\mathrm{NO}_{3}{ }^{-}$supplements can reduce BP and improve EF of the large blood vessels. However, despite the microvasculature being the primary regulator of SVR [53], only a few studies have investigated the short or medium-term use of dietary $\mathrm{NO}_{3}{ }^{-}$on microvascular function.

Contrary to our hypothesis, four weeks of $\mathrm{NO}_{3}{ }^{-}$supplementation did not lead to significant changes in endothelium-dependent or endothelium-independent microvascular reactivity. A potential reason for this null finding could be explained by the pharmacologically vasoactive factors that were administered. Neither, ACh or SNP stimulates the conversion of $\mathrm{NO}_{2}{ }^{-}$into $\mathrm{NO}$, similar to what happens under the ischemic conditions of the FMD procedure. However, Wong et al. stimulated microvascular vasodilation using reactive hyperaemia and found that three days of BRJ supplementation did not alter cutaneous vascular reactivity [54]. The authors proposed that cutaneous reactive hyperaemia is not NO mediated and is rather to be largely dependent on cutaneous sensory-nerve and/or calcium activated potassium (BKCa) channels [55]. It should be noted that this group used laser Doppler flowmetry to measure cutaneous blood flux, which only measures perfusion at a single point. Importantly, laser Doppler imaging scans a larger region of interest and thereby accounts for the spatial heterogeneity of skin blood flow [56]. Therefore, further research is warranted in order to investigate the effects of $\mathrm{NO}_{3}{ }^{-}$supplements on the microcirculation.

The participants for the present pilot study were recruited from a healthy aging population and most of them showed no signs of hypertension. Although significant improvements in large-vessel EF and BP were observed after two weeks within the BRJ group, it was not expected for improvements to continue indefinitely due to the good health of the participants. However, the changes in plasma $\mathrm{NO}_{3}{ }^{-}$ levels corresponded with the changes in $\mathrm{BP}$, thus when plasma $\mathrm{NO}_{3}{ }^{-}$levels decreased from two weeks to four weeks, BP increased. Therefore, an alternative reason why improvements were not sustained for the duration of the study could be explained by the reductions in circulating $\mathrm{NO}_{3}{ }^{-}$. The exact cause of the diminished $\mathrm{NO}_{3}{ }^{-}$availability is not known. Some authors believe that $\mathrm{NO}_{3}{ }^{-}$and $\mathrm{NO}_{2}{ }^{-}$ clearance is upregulated with prolonged exposure [57], however, compliance to this intervention was only confirmed verbally, therefore we are unsure if every participant adhered to their allocated drinks.

\section{Limitations}

A limitation of the present pilot study was the small sample size, due to difficulty with recruitment. A-priori sample size calculation was not performed and therefore we are unable to confirm whether the findings are adequately powered and the result should be interpreted with caution. Additionally, as previously mentioned, compliance to the intervention was only confirmed verbally at the end of the trial; but biological markers did support this declaration to an extent. Although plasma $\mathrm{NO}_{3}{ }^{-}$ levels were measured, we did not have the facilities to analyse $\mathrm{NO}_{2}{ }^{-}$concentrations. Previous finding suggests that significant increases in plasma $\mathrm{NO}_{2}{ }^{-}$occur alongside increases in plasma $\mathrm{NO}_{3}{ }^{-}$in elderly people with T2D [30]. Unfortunately, we were unable to analyse plasma $\mathrm{NO}_{3}{ }^{-}$nor $\mathrm{NO}_{3}{ }^{-}$reducing 
bacteria for all our participants, but the available data suggests that we did not recruit non-responders. Furthermore, it should be noted that the 12 participants who were included for these assessments were not necessarily the same individuals. The large variation in microvascular flux between groups at baseline was also a limitation of the present study. While we accounted for this difference during analysis of the follow-up visits, we are unclear about the exact reason for this difference.

\section{Conclusions}

In conclusion, this pilot study demonstrated that medium-term BRJ ingestion potentially improves SBP, DBP and large-vessel EF in healthy older adults. These changes corresponded to the changes in plasma $\mathrm{NO}_{3}{ }^{-}$levels. Although no changes in microvascular function were observed, further prospective studies examining the long-term impact of $\mathrm{NO}_{3}{ }^{-}$supplementation on this vascular bed in patient populations at risk of CVD are warranted.

Author Contributions: Conceptualization: A.S.; Methodology: A.S., T.J., E.L.D. and H.-P.K.; Supervision: A.S., J.H.M.; T.J. and E.L.D.; Data analysis: T.J., E.L.D. and N.M.; Writing-original draft preparation: T.J.; Writing-review and editing: A.S., T.J., H.-P.K. and J.H.M.; Funding acquisition: A.S. All authors read and approved the final manuscript.

Funding: Funding for this study was received from the research funds of Aamer Sandoo.

Acknowledgments: The authors would like to thank Reece Smith, William Mapus-Smith and Jodie Palmer for their support with data collection. Additionally, we thank Kevin Williams and Jason Edwards for their technical assistance. We also thank all the participants who took part in the study.

Conflicts of Interest: The authors declare no conflicts of interest.

\section{References}

1. Sandoo, A.; Veldhuijzen van Zanten, J.J.C.S.; Metsios, G.S.; Carroll, D.; Kitas, G.D. The Endothelium and Its Role in Regulating Vascular Tone. Open Cardiovasc. Med. J. 2010, 4, 302-312. [CrossRef] [PubMed]

2. Furchgott, R.F.; Zawadzki, J.V. The obligatory role of endothelial cells in the relaxation of arterial smooth muscle by acetylcholine. Nature 1980, 288, 373-376. [CrossRef] [PubMed]

3. Seals, D.R.; Jablonski, K.L.; Donato, A.J. Aging and vascular endothelial function in humans. Clin. Sci. 2011, 120, 357-375. [CrossRef] [PubMed]

4. Sverdlov, A.L.; Ngo, D.T.M.; Chan, W.P.A.; Chirkov, Y.Y.; Horowitz, J.D. Aging of the Nitric Oxide System: Are We as Old as Our NO? J. Am. Heart Assoc. 2014, 3, e000973. [CrossRef] [PubMed]

5. Benjamin, N.; O’Driscoll, F.; Dougall, H.; Duncan, C.; Smith, L.; Golden, M.; McKenzie, H. Stomach NO synthesis. Nature 1994, 368, 502. [CrossRef] [PubMed]

6. Lundberg, J.O.; Govoni, M. Inorganic nitrate is a possible source for systemic generation of nitric oxide. Free Radic. Biol. Med. 2004, 37, 395-400. [CrossRef] [PubMed]

7. Cosby, K.; Partovi, K.S.; Crawford, J.H.; Patel, R.P.; Reiter, C.D.; Martyr, S.; Yang, B.K.; Waclawiw, M.A.; Zalos, G.; Xu, X.; et al. Nitrite reduction to nitric oxide by deoxyhemoglobin vasodilates the human circulation. Nat. Med. 2003, 9, 1498-1505. [CrossRef]

8. Shiva, S.; Huang, Z.; Grubina, R.; Sun, J.; Ringwood, L.A.; MacArthur, P.H.; Xu, X.; Murphy, E.; Darley-Usmar, V.M.; Gladwin, M.T. Deoxymyoglobin is a Nitrite Reductase That Generates Nitric Oxide and Regulates Mitochondrial Respiration. Circ. Res. 2007, 100, 654-661. [CrossRef]

9. Webb, A.J.; Patel, N.; Loukogeorgakis, S.; Okorie, M.; Aboud, Z.; Misra, S.; Rashid, R.; Miall, P.; Deanfield, J.; Benjamin, N.; et al. Acute Blood Pressure Lowering, Vasoprotective, and Antiplatelet Properties of Dietary Nitrate via Bioconversion to Nitrite. Hypertension 2008, 51, 784-790. [CrossRef]

10. Zweier, J.L.; Wang, P.; Samouilov, A.; Kuppusamy, P. Enzyme-independent formation of nitric oxide in biological tissues. Nat. Med. 1995, 1, 804-809. [CrossRef]

11. Nohl, H.; Staniek, K.; Sobhian, B.; Bahrami, S.; Redl, H.; Kozlov, A.V. Mitochondria recycle nitrite back to the bioregulator nitric monoxide. Acta Biochim. Pol. 2000, 47, 913-921. [PubMed]

12. Lundberg, J.O; Weitzberg, E.; Gladwin, M.T. The nitrate-nitrite-nitric oxide pathway in physiology and therapeutics. Nat. Rev. Drug Discov. 2008, 7, 156-167. [CrossRef] 
13. Jackson, J.K.; Patterson, A.J.; MacDonald-Wicks, L.K.; Oldmeadow, C.; McEvoy, M.A. The role of inorganic nitrate and nitrite in cardiovascular disease risk factors: A systematic review and meta-analysis of human evidence. Nutr. Rev. 2018, 76, 348-371. [CrossRef] [PubMed]

14. Liu, A.H.; Bondonno, C.P.; Russell, J.; Flood, V.M.; Lewis, J.R.; Croft, K.D.; Woodman, R.J.; Lim, W.H.; Kifley, A.; Wong, G.; et al. Relationship of dietary nitrate intake from vegetables with cardiovascular disease mortality: A prospective study in a cohort of older Australians. Eur. J. Nutr. 2018. [CrossRef] [PubMed]

15. Blekkenhorst, L.C.; Bondonno, C.P.; Lewis, J.R.; Devine, A.; Woodman, R.J.; Croft, K.D.; Lim, W.H.; Wong, G.; Beilin, L.J.; Prince, R.L.; et al. Association of dietary nitrate with atherosclerotic vascular disease mortality: A prospective cohort study of older adult women. Am. J. Clin. Nutr. 2017, 106, 207-216. [CrossRef] [PubMed]

16. Capurso, C.; Massaro, M.; Scoditti, E.; Vendemiale, G.; Capurso, A. Vascular effects of the Mediterranean diet Part I: Anti-hypertensive and anti-thrombotic effects. Vascul. Pharmacol. 2014, 63, 118-126. [CrossRef]

17. Sobko, T.; Marcus, C.; Govoni, M.; Kamiya, S. Dietary nitrate in Japanese traditional foods lowers diastolic blood pressure in healthy volunteers. Nitric Oxide 2010, 22, 136-140. [CrossRef] [PubMed]

18. Velmurugan, S.; Gan, J.M.; Rathod, K.S.; Khambata, R.S.; Ghosh, S.M.; Hartley, A.; Van Eijl, S.; Sagi-Kiss, V.; Chowdhury, T.A.; Curtis, M.; et al. Dietary nitrate improves vascular function in patients with hypercholesterolemia: A randomized, double-blind, placebo-controlled study. Am. J. Clin. Nutr. 2016, 103, 25-38. [CrossRef] [PubMed]

19. Kapil, V.; Khambata, R.S.; Robertson, A.; Caulfield, M.J.; Ahluwalia, A. Dietary Nitrate Provides Sustained Blood Pressure Lowering in Hypertensive Patients. Hypertension 2015, 65, 320-327. [CrossRef] [PubMed]

20. Jajja, A.; Sutyarjoko, A.; Lara, J.; Rennie, K.; Brandt, K.; Qadir, O.; Siervo, M. Beetroot supplementation lowers daily systolic blood pressure in older, overweight subjects. Nutr. Res. 2014, 34, 868-875. [CrossRef]

21. Khambata, R.S.; Ghosh, S.M.; Rathod, K.S.; Thevathasan, T.; Filomena, F.; Xiao, Q.; Ahluwalia, A. Antiinflammatory actions of inorganic nitrate stabilize the atherosclerotic plaque. Proc. Natl. Acad. Sci. USA 2017, 114, E550-E559. [CrossRef] [PubMed]

22. Ghosh, S.M.; Kapil, V.; Fuentes-Calvo, I.; Bubb, K.J.; Pearl, V.; Milsom, A.B.; Khambata, R.; Maleki-Toyserkani, S.; Yousuf, M.; Benjamin, N.; et al. Enhanced Vasodilator Activity of Nitrite in Hypertension. Hypertension 2013, 61, 1091-1102. [CrossRef] [PubMed]

23. Kelly, J.; Fulford, J.; Vanhatalo, A.; Blackwell, J.R.; French, O.; Bailey, S.J.; Gilchrist, M.; Winyard, P.G.; Jones, A.M. Effects of short-term dietary nitrate supplementation on blood pressure, $\mathrm{O}_{2}$ uptake kinetics, and muscle and cognitive function in older adults. Am. J. Physiol. Integr. Comp. Physiol. 2013, 304, R73-R83. [CrossRef] [PubMed]

24. Hobbs, D.A.; Kaffa, N.; George, T.W.; Methven, L.; Lovegrove, J.A. Blood pressure-lowering effects of beetroot juice and novel beetroot-enriched bread products in normotensive male subjects. Br. J. Nutr. 2012, 108, 2066-2074. [PubMed]

25. Kapil, V.; Milsom, A.B.; Okorie, M.; Maleki-Toyserkani, S.; Akram, F.; Rehman, F.; Arghandawi, S.; Pearl, V.; Benjamin, N.; Loukogeorgakis, S.; et al. Inorganic Nitrate Supplementation Lowers Blood Pressure in Humans. Hypertension 2010, 56, 274-281. [CrossRef] [PubMed]

26. Triggle, C.R.; Ding, H. The endothelium in compliance and resistance vessels. Front. Biosci. (Schol. Ed.) 2011, 3, 730-744. [PubMed]

27. Houben, A.J.H.M.; Martens, R.J.H.; Stehouwer, C.D.A. Assessing Microvascular Function in Humans from a Chronic Disease Perspective. J. Am. Soc. Nephrol. 2017, 28, 3461-3472. [CrossRef] [PubMed]

28. Aird, W.C. Phenotypic Heterogeneity of the Endothelium. Circ. Res. 2007, 100, 158-173. [CrossRef] [PubMed]

29. Sandoo, A.; Carroll, D.; Metsios, G.S.; Kitas, G.D.; Veldhuijzen van Zanten, J.J. The association between microvascular and macrovascular endothelial function in patients with rheumatoid arthritis: A cross-sectional study. Arthritis Res. Ther. 2011, 13, R99. [CrossRef]

30. Gilchrist, M.; Winyard, P.G.; Aizawa, K.; Anning, C.; Shore, A.; Benjamin, N. Effect of dietary nitrate on blood pressure, endothelial function, and insulin sensitivity in type 2 diabetes. Free Radic. Biol. Med. 2013, 60, 89-97. [CrossRef]

31. Roustit, M.; Cracowski, J.-L. Assessment of endothelial and neurovascular function in human skin microcirculation. Trends Pharmacol. Sci. 2013, 34, 373-384. [CrossRef] [PubMed]

32. Craig, C.L.; Marshall, A.L.; Sjöström, M.; Bauman, A.E.; Booth, M.L.; Ainsworth, B.E.; Pratt, M.; Ekelund, U.; Yngve, A.; Sallis, J.F.; et al. International physical activity questionnaire: 12-country reliability and validity. Med. Sci. Sports Exerc. 2003, 35, 1381-1395. [CrossRef] [PubMed] 
33. Berry, M.J.; Justus, N.W.; Hauser, J.I.; Case, A.H.; Helms, C.C.; Basu, S.; Rogers, Z.; Lewis, M.T.; Miller, G.D. Dietary nitrate supplementation improves exercise performance and decreases blood pressure in COPD patients. Nitric Oxide 2015, 48, 22-30. [CrossRef] [PubMed]

34. McMahon, N.; Pavey, T.; Desbrow, B.; Leveritt, M. Developing of a nitrate, nitrite, and nitrosamines food and beverage composition database for use with a food frequency questionnaire: A Systematic Review. Unpubl. Manuscr. 2017, 20 (suppl. 3), 22. [CrossRef]

35. Griesenbeck, J.S.; Steck, M.D.; Huber, J.C.; Sharkey, J.R.; Rene, A.A.; Brender, J.D. Development of estimates of dietary nitrates, nitrites, and nitrosamines for use with the short willet food frequency questionnaire. Nutr. J. 2009, 8, 16. [CrossRef] [PubMed]

36. Honikel, K.-O. The use and control of nitrate and nitrite for the processing of meat products. Meat Sci. 2008, 78, 68-76. [CrossRef]

37. Walker, R. Nitrates, nitrites and N-nitrosocompounds: A review of the occurrence in food and diet and the toxicological implications. Food Addit. Contam. 1990, 7, 717-768. [CrossRef] [PubMed]

38. Foodworks. Research Edition (v9) [Computer Software] Brisbane, Qld: Xyris Software. 2019. Available online: https://foodworks.com.au/ (accessed on 5 June 2019).

39. Nutritics. Research Edition (v5.02) [Computer Software]. Dublin. 2018. Available online: www.nutritics.com (accessed on 5 June 2019).

40. Schakel, S.F.; Buzzard, I.M.; Gebhardt, S.E. Procedures for Estimating Nutrient Values for Food Composition Databases. J. Food Compos. Anal. 1997, 10, 102-114. [CrossRef]

41. Sandoo, A.; Kitas, G.D. A Methodological Approach to Non-invasive Assessments of Vascular Function and Morphology. J. Vis. Exp. 2015, 1-8. [CrossRef] [PubMed]

42. Ndiaye, B.P.; Thienemann, F.; Ota, M.; Landry, B.S.; Camara, M.; Dièye, S.; Dieye, T.N.; Esmail, H.; Goliath, R.; Huygen, K.; et al. Safety, immunogenicity, and efficacy of the candidate tuberculosis vaccine MVA85A in healthy adults infected with HIV-1: A randomised, placebo-controlled, phase 2 trial. Lancet Respir. Med. 2015, 3, 190-200. [CrossRef]

43. Rodriguez-Miguelez, P.; Seigler, N.; Harris, R.A. Ultrasound Assessment of Endothelial Function: A Technical Guideline of the Flow-mediated Dilation Test. J. Vis. Exp. 2016. [CrossRef] [PubMed]

44. Thijssen, D.H.J.; Black, M.A.; Pyke, K.E.; Padilla, J.; Atkinson, G.; Harris, R.A.; Parker, B.; Widlansky, M.E.; Tschakovsky, M.E.; Green, D.J. Assessment of flow-mediated dilation in humans: A methodological and physiological guideline. Am. J. Physiol. Circ. Physiol. 2011, 300, H2-H12. [CrossRef] [PubMed]

45. Atkinson, G.; Batterham, A.M. Allometric scaling of diameter change in the original flow-mediated dilation protocol. Atherosclerosis 2013, 226, 425-427. [CrossRef] [PubMed]

46. Granger, D.L.; Taintor, R.R.; Boockvar, K.S.; Hibbs, J.B. Measurement of nitrate and nitrite in biological samples using nitrate reductase and Griess reaction. Methods Enzymol. 1996, 268, 142-151. [PubMed]

47. Miranda, K.M.; Espey, M.G.; Wink, D.A. A Rapid, Simple Spectrophotometric Method for Simultaneous Detection of Nitrate and Nitrite. Nitric Oxide 2001, 5, 62-71. [CrossRef] [PubMed]

48. Jadhav, S.; Sattar, N.; Petrie, J.R.; Cobbe, S.M.; Ferrell, W.R. Reproducibility and repeatability of peripheral microvascular assessment using iontophoresis in conjunction with laser Doppler imaging. J. Cardiovasc. Pharmacol. 2007, 50, 343-349. [CrossRef] [PubMed]

49. Franklin, S.S.; Thijs, L.; Hansen, T.W.; O’Brien, E.; Staessen, J.A. White-Coat Hypertension. Hypertension 2013, 62, 982-987. [CrossRef]

50. Siervo, M.; Lara, J.; Ogbonmwan, I.; Mathers, J.C. Inorganic Nitrate and Beetroot Juice Supplementation Reduces Blood Pressure in Adults: A Systematic Review and Meta-Analysis. J. Nutr. 2013, 143, 818-826. [CrossRef]

51. Carlström, M.; Lundberg, J.O.; Weitzberg, E. Mechanisms underlying blood pressure reduction by dietary inorganic nitrate. Acta Physiol. 2018, 224, e13080. [CrossRef]

52. Bond, V.; Curry, B.H.; Adams, R.G.; Asadi, M.S.; Millis, R.M.; Haddad, G.E. Effects of Dietary Nitrates on Systemic and Cerebrovascular Hemodynamics. Cardiol. Res. Pract. 2013, 2013, 1-9. [CrossRef]

53. Pries, A.R.; Secomb, T.W.; Gaehtgens, P. Structural Autoregulation of Terminal Vascular Beds. Hypertension 1999, 33, 153-161. [CrossRef] [PubMed]

54. Wong, B.J.; Keen, J.T.; Levitt, E.L. Cutaneous reactive hyperaemia is unaltered by dietary nitrate supplementation in healthy humans. Clin. Physiol. Funct. Imaging 2018, 38, 772-778. [CrossRef] [PubMed] 
55. Lorenzo, S.; Minson, C.T. Human cutaneous reactive hyperaemia: Role of BK Ca channels and sensory nerves. J. Physiol. 2007, 585, 295-303. [CrossRef] [PubMed]

56. Turner, J.; Belch, J.J.F.; Khan, F. Current Concepts in Assessment of Microvascular Endothelial Function Using Laser Doppler Imaging and Iontophoresis. Trends Cardiovasc. Med. 2008, 18, 109-116. [CrossRef] [PubMed]

57. Marsch, E.; Theelen, T.L.; Janssen, B.J.A.; Briede, J.J.; Haenen, G.R.; Senden, J.M.G.; van Loon, L.J.C.; Poeze, M.; Bierau, J.; Gijbels, M.J.; et al. The effect of prolonged dietary nitrate supplementation on atherosclerosis development. Atherosclerosis 2016, 245, 212-221. [CrossRef] [PubMed]

(C) 2019 by the authors. Licensee MDPI, Basel, Switzerland. This article is an open access article distributed under the terms and conditions of the Creative Commons Attribution (CC BY) license (http://creativecommons.org/licenses/by/4.0/). 